\title{
LOS JUEGOS OLÍMPICOS, PROGRAMA PARA UN ANÁLISIS. “EL ESPECTÁCULO MÁS DIFUNDIDO POR LA TELEVISIÓN EN EL MUNDO"
}

\section{THE OLYMPIC GAMES, PROGRAM FOR AN ANALYSIS. THE MOST BROADCASTED SHOW ON T.V. AROUND THE WORLD}

\author{
Luz Stella Ramírez Alarcón ${ }^{1}$
}

${ }_{1}^{1}$ Profesional en Deporte y Actividad Física. Especialista en Dirección y Gestión Deportiva. c. Magíster en Sociología. Docente Institución Universitaria Escuela Nacional del Deporte, Valle del Cauca-Santiago de Cali, Calle 9 No.34-01. comunicaciones@ endeporte.edu.co, practica_pedagogica@endeporte.edu.co

Rev. U.D.C.A Act. E Div. Cient. 15 (Supl. Olimpismo): 13 - 16, 2012

\section{RESUMEN}

El artículo presenta una reseña crítica sobre el texto "LOS JUEGOS OLÍMPICOS, PROGRAMA PARA UIN ANÁLISIS - "El espectáculo más difundido por la televisión en el mundo", uno de los anexos del libro sobre la televisión, del francés Pierre Bourdieu. Por las características de reseña crítica permite la interpelación al autor del libro, a partir de la reflexión que se realiza sobre los Juegos Olímpicos y tal análisis se forja a la luz del autor, quien expone su planteamiento desde la perspectiva sociológica. Adicionalmente, se establece la relación entre algunas de las definiciones realizadas por el autor y las de otros, quienes abordan el deporte y permite enfrentar, de forma provocadora, la intención de los medios de comunicación masivos y la manera como éstos mercadean el deporte, como una suerte de producto comercial, para ganar audiencia masiva; todo esto en el marco del desarrollo de los Juegos Olímpicos.

Palabras clave: Juegos Olímpicos, televisión, audiencia, mercadeo.

\section{SUMMARY}

This article presents a critical review of the text "OLYMPIC GAMES, PROGRAM FOR ANALYSIS. - "The most televised program in the world", one of the annexes to the book "On TV" by the french author Pierre Bourdieu. The characteristics of critical review, allows the questioning of the aforementioned book author from the reflection that takes place on the Olympic Games and that analysis is shaped in the light of the author, who presents his approach from a sociological perspective. Additionally, it establishes the relationship between some of the definitions made by the author, and those made by other authors who approach the sport and allows provocatively confront the intention of the media and the way they market the sport as a kind commercial product to gain mass audience, all in the context of the development of the Olympic Games.

Key words: Olympic Games, show, T.V, marketing.

\section{INTRODUCCIÓN}

Actualmente, hablar sobre la relación entre la televisión y el deporte es un gran reto; sin embargo, en ese intento por comprender algunos de sus componentes principales, se presenta la reseña: "Los Juegos Olímpicos: Programa para un análisis, cuyo texto hace parte de una ponencia presentada en la reunión de la Sociedad Filosófica para el estudio del deporte, llevada a cabo en Berlín, el 2 de octubre de 1992, de los anexos del libro "Sobre la Televisión", de Pierre Bourdieu. El libro está compuesto por dos conferencias del curso que el autor ofrecía en el Collège de France, en el que realiza todo un análisis de la televisión y en el que incluye un anexo sobre los Juegos Olímpicos (Comité Olímpico Internacional, 2001). 
El autor explica los efectos que la televisión tiene sobre la sociedad en nuestros días y expone, particularmente, el resultado que tiene en el espectáculo más grande del deporte a nivel mundial: "Los Juegos Olímpicos", cuando se graban y se difunden en un sin número de países del planeta, cada cuatro años. De esta manera, como se trata de uno de los anexos del libro, es necesario precisar que esta reseña crítica, abordará, específicamente, el tema de los Juegos Olímpicos, interpelando algunas ideas planteadas por Bourdieu.

En este orden de ideas, el texto está construido en dos partes, esencialmente. La primera, expone las ideas sustentadas por el autor en el anexo denominado "Los Juegos Olímpicos: Programa para una análisis", donde, fundamentalmente, sustenta que los medios de comunicación masivos cada vez alcanzan mayor protagonismo en el panorama político, tanto en la esfera nacional como internacional y resaltan su activa participación como transformadores de la realidad de los televidentes, a través de la difusión de los Juegos Olímpicos, como el espectáculo más divulgado por las cadenas de difusión televisiva del mundo.

De la misma manera, se establece la relación entre algunas definiciones dadas por Bourdieu y las expuestas por otros autores, quienes abordan el mismo tópico.

La segunda parte del texto converge en una crítica provocadora sobre cómo los medios de comunicación masivos, particularmente la televisión, mercadean el deporte, como un producto comercial, con la intención de obtener audiencia masiva, sometiéndose, en última instancia, a las lógicas del mercado en forma de imposición comercial, donde los medios actúan como constructores de una representación deformada de la realidad y está en el marco de los Juegos Olímpicos.

\section{CAPÍTULO I: VISIÓN DE BOURDIEU SOBRE LOS JUEGOS OLÍMPICOS}

En principio, el cuestionamiento que Bourdieu (1996) hace a los lectores "¿Qué entendemos exactamente cuando hablamos de Juegos Olímpicos?”, es casi imposible no sospechar que su intención es abrir la discusión sobre el tema, razón, por la cual, esta reseña del texto permite darle respuesta al autor, quien desde una mirada sociológica del deporte valora los Juegos Olímpicos, como un majestuoso evento universal.

De este modo y para poder entender y dimensionar los Juegos Olímpicos como espectáculo deportivo, Bourdieu (1996) propone entenderlo como:

"[...] la manifestación de un espectáculo propiamente deportivo, una confrontación entre atletas procedentes de todo el mundo que se lleva a cabo en nombre de unos ideales universalistas, y un ritual, de marcado tono nacional, cuando no nacionalista, con desfile de los equipos de diversos países y entrega de medallas solemnizadas con banderas e himnos". El mensaje oculto, se encuentra a través de ese conjunto de representaciones de ese espectáculo que filman y que difunden las cadenas de televisión, de los diferentes países.

Aunque para realizar el análisis de lo que aquí plantea el autor, se debe partir, en primer lugar, de otras definiciones de Juegos Olímpicos y recordar, tal como lo afirma Salvador (2009): "aquellas ceremonias religiosas, algunas tipo ritual funerario que en la antigüedad no solo tenían lugar en Olimpia, sino también en otras ciudades en las que realizaban todo tipo de festividades, y en las que se reflejaba la lucha entre dos contendientes y cuya presencia de los dioses Griegos era el punto de partida". Así y en coherencia con lo anterior, se le atribuyó al gran dios mayor del Olimpo, Zeus, la dedicación y el culto de los Helenos, por medio de manifestaciones deportivas expresadas en competencias, llamadas Olimpiadas (Rodríguez, 2008). En la antigüedad, se le denominaba Olimpiadas al desarrollo de las competencias de los griegos, cuyo contenido es similar a las disciplinas deportivas practicadas en la actualidad y presentadas dentro del programa de los Juegos Olímpicos, en sus versiones de verano e invierno.

En este orden de ideas, los Juegos Olímpicos, a partir de su resurgimiento en la modernidad, se definieron y se instauraron como el programa de disciplinas deportivas, que reúne los jóvenes del mundo, en el evento de competición deportiva más importante del planeta. Una reciente publicación (Editorial Televisa Internacuonal, 2008), destaca la importancia de no obviar en este escrito a su precursor, el pedagogo Francés Pierre de Frédy de Coubertín, quien en 1986 y en el momento de la celebración de los primeros Juegos Olímpicos del mundo contemporáneo, en Atenas, expresó: "Espero que el renacimiento de los Juegos Olímpicos conduzca al atletismo a un alto grado de perfección y que infunda nuevos elementos de ambición a las vidas de la actual generación: iel amor por la concordia y el respeto a la vida". Esto significa, que tales competencias son la manifestación más grande del deporte de alto rendimiento y al que sólo llegan los atletas de más alto nivel.

De ésta y en acuerdo con Bourdieu, los Juegos Olímpicos son el espectáculo deportivo más grande del planeta, en el que confluyen las disciplinas deportivas más practicadas en el mundo y donde únicamente se pueden incluir aquellas ampliamente realizadas en, al menos, 75 países, en cuatro continentes ejecutadas por hombres y, en tres continentes, por mujeres, en la versión de verano y, al menos, 25 países 
y en tres continentes, para la versión de invierno. El Comité Olímpico Internacional garantiza su celebración periódica cada cuatro años, en su manifestación de verano e invierno, de acuerdo a los parámetros establecidos por el Movimiento Olímpico (conjunto de organizaciones deportivas, atletas y otras personas reconocidas por el Comité Olímpico), en torno a la competencia más exigente entre los diferentes países del mundo, representados en los cinco continentes.

Si bien, las definiciones de los Juegos Olímpicos se acercan un poco es indispensable entender el significado del deporte de altos logros, pues es a partir de éste, donde confluyen los resultados de la preparación de más alto nivel en el deporte y en el que se establecen diversas fuerzas, a veces armónicas, a veces disonantes, entretejidas en las tensiones de los diversos campos (espacio social estructurado, donde se presentan dominantes y dominados), que participan en el desarrollo de este magno evento. Y si de campos hablamos, reconocer el de los medios de comunicación resulta fundamental para indicar, cómo dichos medios terminan condenando los objetivos e intencionalidades reales de los Juegos Olímpicos, mientras que como lo afirma Bourdieu (1996), "existe otra realidad, la del espectador que está situado en alguna parte, en cualquier país y tiene la ilusión de ver el espectáculo olímpico en su verdad y a través del televisor de su casa".

\section{CAPÍTULO II: INTERPELACIÓN A BOURDIEU Y CRÍTICA A LA TELEVISIÓN COMO MEDIO DE COMUNICACIÓN}

Para Bourdieu, la televisión tiene un carácter internacional, pues transmite un certamen universal, pero es nacional, en el sentido que otorga el espacio al atleta participante o a una disciplina deportiva de los Juegos Olímpicos. En consecuencia, la representación televisiva de los atletas está presente como grabación del hecho deportivo y transforma, al mismo tiempo, la particularidad de la competencia, en tanto provienen de diversas partes del mundo y son vistos en toda la esfera universal, como delegados de su Nación.

No basta, entonces, con reconocer las consecuencias del hecho deportivo representado en el atleta procedente de un país; también es importante interpretar su consecuencia, al ser parte del proceso de transmutación simbólica, examinado a la luz de la construcción social del espectáculo deportivo en sí mismo y de las consecuencias que se manifiestan de forma colateral en un segundo orden, como son los actos protocolarios de inauguración del certamen, la instalación de cada torneo y la clausura de todo el evento; sin embargo, el autor propone:
"Tomar como objeto el conjunto del campo de producción de los Juegos Olímpicos en tanto que espectáculo televisado, o mejor aún, en el lenguaje del marketing, en tanto utensilio de comunicación, es decir, el conjunto de relaciones objetivas entre los agentes y las instituciones comprometidas en la competencia por la producción y la comercialización de las imágenes y los discursos sobre los juegos" (Bourdieu, 1968).

Todo lo anteriormente señalado, se inscribe en ese lenguaje cifrando entre líneas, tal vez, al que no todos quieren prestar atención, pues en su mayoría el extasío del magno evento deportivo no se los permite, pero que soterradamente ofrecen un mundo de comercialización de los deportistas. Frente a esto, Bourdieu realiza una feroz crítica a la "progresiva" empresa en la que se ha convertido, a su juicio, el Comité Olímpico Internacional, pues afirma que el millonario presupuesto con el que cuenta está dominado por su pequeño grupo de dirigentes y en coalición con las grandes empresas, como Adidas, Coca-Cola, entre otras, que controlan los derechos de retransmisión del evento, los cuales, ascienden a cifras multimillonarias. Así, pone también en consideración que: "los efectos de la intensificación de la competencia entre las naciones que la televisión ha producido a través de la planetarización del espectáculo Olímpico como la aparición de políticas deportivas estatales, orientadas hacia los éxitos internacionales, la explotación simbólica económica y las victorias de la industrialización de la producción deportiva que implica recurrir al dopaje y a formas autoritarias de entrenamiento".

Desde este enfoque, el autor toca álgidos puntos en la esfera del deporte "de élite" y es oportuno considerar que en una perspectiva socio-económica auscultada a la luz de la industrialización deportiva, se relaciona la aparición del récord deportivo, como la consecuencia del éxito en las apuestas (Brohm, 1982), lo cual, en la actualidad, es identificable con la concurrencia al dopaje, con el objetivo de mantener el monopolio económico de aquellos que solapan su interés lucrativo tras las competencias deportivas de altísimo nivel, como lo son los campeonatos mundiales o, en este caso particular, sobre el que llamamos la atención, los Juegos Olímpicos.

Entender que ese tipo de industrialización no solo es una derivación del crecimiento voraz del Comité Olímpico Internacional de esta época, sino que manifiesta la evolución misma del deporte asociado (en él se inscribe el deporte de élite), desde tiempos atrás, en la modernidad, cuando el deporte se constituyó como un modo más de producción del capitalismo, el que crece paralelamente con el desarrollo deportivo, en todos sus aspectos. 
Asimismo, la concurrencia al dopaje no solo es producto de la presión ejercida por las fuerzas económicas que subyacen y que operan tras los mensajes de televisión, a través de sus actores principales (los periodistas), también es consecuencia de los adelantos tecnológicos que han permitido no solo mejorar los métodos de entrenamiento, sino optimizar las capacidades individuales de cada atleta en el mundo, de manera particular.

\section{CONCLUSIONES}

El autor convoca a los agentes del periodismo encargados de transmitir el evento deportivo más importante del mundo a instaurar nuevas formas para su realización, a partir de la crítica propia de su profesión, pero desde una apuesta ciudadana, es decir, desde su función de información y de comunicación de una realidad histórica y con gran contenido nacionalista, evidenciada en la representación de cada país, por medio de los mejores atletas del mundo y donde su demostración se exalta al transformar dicha realidad en discurso.

En contraposición a Bourdieu, la intención del Comité Olímpico Internacional (2001), no solo es tener a cuestas la responsabilidad de desarrollar los Juegos Olímpicos, sino también la de contribuir con la masificación del deporte en todo el mundo, por medio de diversos programas, en todos los niveles y en todas la naciones adscritas a él, mediante uno de sus programas rectores, el de Solidaridad Olímpica, el cual, busca integrar las personas de los diversos países, a través del deporte; aunque eso lo haga paradójicamente con parte de los recursos que se capturan en las trasmisiones de los Juegos olímpicos. Pareciera, entonces, que los objetivos y las disposiciones del Comité Olímpico Internacional (2001) se encuentran ocultos a los ojos de los periodistas y, por tanto, a ellos no los pueden informar o, tal vez, simplemente olvidan hacerlo, ya que quizá dichos objetivos no se convierten en índices de audiencia, cuyo desenlace sea causar sensación en el mercado.

\section{BIBLIOGRAFÍA}

1. BOURDIEU, P. 1996. Sobre la Televisión, Barcelona, Ed. Anagrama S.A. p.119-124.

2. BOURDIEU, P. 1968. Structuralism and theory of sociological knowledge. Social Res. 35(4):681-706.

3. BROHM, J. 1982. Sociología política del deporte, Ed. FCE. p.102-107.
4. COMITÉ OLÍMPICO INTERNACIONAL. 2001. Manual de administración deportiva. McAra Printing Limited. Suiza. p.22-34

5. EDITORIAL TELEVISA INTERNACIONAL. 2008. Gran libro de las Olimpiadas. De Atenas 1896 a Beijín 2008. 166p.

6. RODRÍGUEZ, J. 2008. Historia del Deporte. Barcelona, INDE Publicaciones. Barcelona. p.80-82.

7. SALVADOR, J.L. 2009. El deporte en occidente. Ed. Cátedra (Grupo Anaya, S.A). Madrid. p.9-13.

Recibido: Enero 9 de 2012

Aceptado: Abril 13 de 2012 